\title{
The Need to Control for Confounding Factors on Analgesic Studies Involving Bariatric Patients
}

\author{
Daniel Croxford ${ }^{1} \cdot$ Mark C. Kendall $^{1}$ (D)
}

Published online: 18 January 2019

(C) Springer Science+Business Media, LLC, part of Springer Nature 2019

\section{Dear Editor,}

We read with great interest the article of Sisik et al. in a recent issue of the journal [1]. The authors performed a case-control study on 168 patients who underwent laparoscopic sleeve gastrectomy and concluded that factors such as duration of surgery and first flatus time but not the administration of local bupivacaine have an impact on acute pain. The authors should be congratulated for performing a well-designed study in an important topic (e.g., acute pain) in patients undergoing bariatric surgery $[2,3]$. The current emphasis on the need to improve overall postoperative recovery and patient satisfaction makes the topic very important in perioperative medicine $[4,5]$.

Although the study of Sisik et al. was well conducted, there are some critical points that need to be clarified by the authors to determine the validity of the authors' findings. First, the authors do not report the total intraoperative opioid consumption by each study group which is important since it can directly affect the primary outcome. Second, the authors performed multiple analyses but it appears they did not adjust their $p$ values to avoid type I errors. Finally, the data collection performed by clinical nurses has been shown to be biased for analgesic studies and this may have contributed for the lack of an observed effect [6].

We would welcome comments by the authors as this would help to further validate the findings of this important clinical study.
Compliance with Ethical Standards The letter is not a study with human participants. There are no experiments on animals. This letter does not contain any studies on human participants or animals performed by the author. There is no identifying information of participants.

Conflict of Interest The authors declare that they have no conflict of interest.

Publisher's Note Springer Nature remains neutral with regard to jurisdictional claims in published maps and institutional affiliations.

\section{References}

1. Sisik A, Erdem H. Effect of trocar site bupivacaine administration, time of first passage of flatus, and duration of the surgery on postoperative pain after sleeve gastrectomy: a case control study. Obes Surg. 2018. https://doi.org/10.1007/s11695-018-3529-9.

2. Kamarajah SK, Sowida M, Reihill C. Evaluation on preoperative assessment of obese patients. J Clin Anesth. 2017;37:179-80.

3. Wallén S, Szabo E, Palmetun-Ekbäck M, et al. Use of opioid analgesics before and after gastric bypass surgery in Sweden: a population-based study. Obes Surg. 2018;28:3518-23. https://doi.org/10.1007/s11695-018-3377-7.

4. Sangkum L, Klair I, Limsuwat C, et al. Incorporating body-type (apple vs. pear) in STOP-BANG questionnaire improves its validity to detect OSA. J Clin Anesth. 2017;41:126-31.

5. Chen Z, Tang R, Zhang R, et al. Effects of dexmedetomidine administered for postoperative analgesia on sleep quality in patients undergoing abdominal hysterectomy. J Clin Anesth. 2017;36:118-22.

6. Mccarthy RJ, De Oliveira GS. The trouble with using provider assessments for rating clinical performance: it's a matter of bias. Anesth Analg. 2015;120:714-6.
Mark C. Kendall

mark.kendall@lifespan.org

1 Department of Anesthesiology, Rhode Island Hospital, The Warren Alpert Medical School of Brown University, 593 Eddy Street, Providence, RI 02903, USA 